\title{
Prostate Myeloid Sarcoma
}

National Cancer Institute

\section{Source}

National Cancer Institute. Prostate Myeloid Sarcoma. NCI Thesaurus. Code C5527.

Myeloid sarcoma that affects the prostate gland. It may present in association with or as a site of relapse of acute myeloid leukemia. Cases of myeloid sarcoma of the prostate gland preceding acute myeloid leukemia have also been reported. 